\title{
Developing an ICT capability for learning
}

\author{
Steve Kennewell \\ University of Wales Swansea, Department of Education, Hendrefoelan, Swansea SA2 7NB, UK \\ s.e.kennewell@swan.ac.uk
}

\begin{abstract}
Learning effectively with Information and Communication Technology (ICT) requires an appropriate level of ICT capability. This paper explores the ways in which children develop their capability in home and school, and how their skills support ICT activity and learning in each setting. Conditions for developing ICT capability during such activities are identified using a framework for analysing learning situations based on affordances, constraints and abilities. It is concluded that all aspects of young children's ICT capability can be developed effectively through a combination of structured activities in school designed primarily for learning other subjects, provided that subsequent reflective activity is generated. This learning is supported by unstructured activities at home, and provided that they have access to appropriate guidance from more capable family and friends. Suggestions are made concerning the coordination of school and home ICT activities in order to exploit the positive features of each setting, and generate effective learning within and beyond the formal curriculum.
\end{abstract}

Key words: elementary education, conditions for learning, organising for learning, sites of learning

\section{INTRODUCTION}

Evaluations of the role of ICT in learning must consider different perspectives (Squires and MacDougall 1994) and recognise that the influence of ICT is dependent on the ICT capability of the user (Kennewell 2001). What the user knows about ICT affects the quality and quantity of the learning with ICT. The features of ICT that aid learning include interactivity and provisionality (Teacher Training Agency 1998). But to exploit interactivity, the user must know how to respond to screen prompts from the software; in order to exploit provisionality, the user must know how to save, 
load and edit work in progress. If learners do not have sufficient skills in using ICT, they experience the 'ICT interference factor' (Birnbaum 1990), and ICT becomes a barrier rather than an aid to learning.

The ability to use ICT to carry out worthwhile activity, including the learning of subjects other than ICT, has been characterised as ICT Capability (Kennewell, et al. 2000). Five key components of ICT capability have been identified:

- routines such as using a mouse or double clicking on an application;

- techniques such as adjusting margins to make text fit a page;

- key concepts such as menu, file, database, spreadsheet, web site or hypertext link;

- processes such as developing a presentation, seeking information, organising, analysing and presenting the results of a survey;

- higher-order skills and knowledge such as recognising when the use of ICT might be appropriate, planning how to approach a problem, making and testing hypotheses, monitoring progress in a task, evaluating the result, and reflecting on the effect of using ICT in a particular situation. (Kennewell, et al. 2000)

It is anticipated that those skills will develop together during the course of worthwhile tasks across increasingly challenging contexts, with help from those who are more capable.

\section{INFLUENCE OF ICT ON LEARNING}

Learning of specific subject matter is expected to take place through goal-directed activity in which there is a gap between the learning objectives and the student's current knowledge. The "learning gap" is bridged through cognitive effort. The learners utilise the affordances and constraints of the setting, such as those provided by ICT, in combination with their existing abilities in the subject matter to be learned, and in generic skills such as ICT capability. Those abilities, together with the affordances and constraints of the setting, provide both potential and structure for activity (Kennewell 2001). For example, when children are learning about the process of volcano eruption, they may use an encyclopaedia on a CD-ROM. The software affords searching by keyword and by successive focusing on subject headings; it also constrains the user to the specific material that the authors have decided to include. This constraint may be very valuable in the case of encyclopaedias designed especially for young children, although over time it will be unhelpful for children seeking up-to-date information. The CD-ROM does not do all the work and the child must know something about the 
process of searching and the particular techniques needed to carry out the searches with the CD-ROM. Furthermore, merely accessing information may not bring about learning and a reflective stage is an important element of the learning activity (Kennewell 2000).

The information retrieval scenario described above could take place in either home or school. The technological, human and cultural resources will vary between the formal school setting and the more informal setting of home. However, we may expect the differences in the features of the settings to have fundamental effects on the nature and process of children's learning with ICT. Home ICT activity is characterised by "bricolage" and "hard fun" (Papert 1996), whereas school use is largely routine, unstimulating (Kennewell, et al. 2000) and prescriptive (Sutherland, et al. 2000a).

\section{FEATURES OF THE HOME SETTING}

In the UK, the technological resources available in homes are increasingly sophisticated and widespread (Harrison, et. al. 2001). Indeed, many homes contain more sophisticated resources than schools (Kennewell, et al. 2000; Downes 1998), affording more effective presentation and access to greater range of information sources. Other affordances arise from the human and cultural resources available to support activity; for instance, the willingness and ability of parents and other family members to help, their networks of social and professional contacts, and the models of ICT activity that they provide (Sutherland, et al. 2000b).

Children's use of the resources may be constrained in various ways (Sutherland, et al. 2000b; Downes 1998). Table 1 illustrates some of the technological, human and cultural features that constrain home ICT use for children; some may have a positive effect on learning, others are potentially negative.

Table 1. Constraints on home use of ICT

\begin{tabular}{ll}
\hline Constraint & Example \\
\hline Location of resources & $\begin{array}{l}\text { In a communal room } \\
\text { Creparation needed }\end{array}$ \\
& $\begin{array}{l}\text { Connecting a telephone line for Internet } \\
\text { connection }\end{array}$ \\
Parental restriction or security provision & Password protection on Internet filtering \\
Competition of hierarchy with family & Older siblings have priority \\
Perceived role in relation to technology & Feeling of inadequacy in comparison to more \\
& expert members of the family \\
Imposed priorities for different activities & School has priority over games \\
\hline
\end{tabular}




\section{FEATURES OF THE SCHOOL SETTING}

In school, different features are evident. First, the technology is usually based on a network, which affords the sharing of resources created for specific curriculum needs, access to a greater range of specific software and the exchange of ideas between pupils.

Second, the human support is of a professional nature. Many primary schools have appointed a specialist teacher for ICT, and most others have a coordinator for ICT who supports generalist class teachers by helping to produce plans for pupils' progression, schemes of work for each year and tasks designed to promote specific learning objectives. In the classroom, pupils often work in mixed ability pairs, seek help from their friends and "class experts", and increasingly, technicians and classroom assistants provide support for ICT activity (Kennewell, et al. 2000).

Third, the cultural resources are more communal in nature and specific to the planned curriculum. The effect of a whole class working on the same activity is valued by pupils (Kennewell 1993). The teacher expects that pupils will develop their work beyond their initial attempts. The practice of displaying children's work on the classroom and corridor walls, and the more recent adoption of electronic presentations affords the publishing of children's knowledge for the class or even a wider audience.

There are different constraints, too. Some may have a negative effect: School software may be unfamiliar to pupils with expertise developed at home, network crashes may mean computers are unavailable at times, some teachers may not give pupils access to resources which they have not been taught to use. Other constraints are designed to have a positive effect through providing structure for children's learning, such as limiting the time spent on enhancing presentation, focusing Internet use on specific educational web sites, and creating a rota to ensure that all pupils' access to computers is regular and systematic. The requirement to explain to a "less able" peer can also have a positive effect on children's concept formation.

The most significant feature of the school setting, however, is the role of the teacher in setting differentiated tasks that have an appropriate learning gap within a carefully planned curriculum, then orchestrating the affordances and constraints of ICT in a manner that is contingent on pupils' existing and developing abilities, and finally promoting reflection on the activity.

In primary schools in the UK, it is common practice for an ICT task to be introduced to the whole class. Pairs of pupils then work on the activity using one or more computers in the classroom on a rota basis over a number of days. When all children have worked on the task, a whole class plenary session is held in order to question pupils about their work, evaluate their learning, focus their attention on the concepts and skills developed, and 
discuss other applications of the ideas. Furthermore, the teacher will normally plan the ICT task and plan the teacher input to develop the children's knowledge in other curriculum areas as well as developing ICT capability (Kennewell, et al. 2000).

\section{GOALS AND THE MONITORING OF PROGRESS}

Another major difference between the home and the school setting is in the nature of the goals. At home, the goals are largely those of the children, despite the use of "school work" as an argument for acquiring the computer in many cases (Sutherland, et al. 2001b); at school, the goals are largely those of the teacher.

Children view learning using computers at home as a much more pleasant activity than learning from teachers in school. Pupils with computers at home often indicate that they are far more independent in their learning (Kennewell, et al. 2000) and have time for exploration (Sutherland, et al. 2000a). But that independence has implications for learning, both about ICT and with ICT. When there is a learning gap to be bridged, some cognitive effort is required; the child's reaction to the situation is crucial.

There are a number of possible reactions to difficulties in using ICT to solve problems which children have demonstrated in various contexts:

- give up and pursue another activity;

- use an alternative strategy which is inefficient but known to achieve the desired effect;

- ask a more expert child;

- ask an adult (parent, teacher, technician, classroom assistant);

- use the "Help" function;

- consult a printed guide. (Kennewell 2002; Sutherland, et al. 2000a)

Some of the strategies are likely to result in learning, but some will clearly not do so, and for others their effectiveness will depend on how well the support provided matches the ability of the child. In the classroom setting, we can expect the teacher to monitor task progress and the achievement of learning objectives. That approach is not without its problems, since many teachers have not yet developed a high level of expertise in evaluating ICT-based learning, but the children should at least recognise a certain expectation on the part of the teacher and feel accountable for their efforts. In the home, that accountability is largely absent and whether the children learn from their experience depends a lot on their self-regulatory abilities. The locus of control, represented by the choice of activity, time of engagement and depth of study, has a significant effect 
on motivation, concentration and perseverance. The trial-and-error approach, characteristic of home activity, may therefore be successful in achieving an outcome for the task. This is a weak strategy for solving problems, however, and, without a reflective stage, it is likely that little will have been learned either in ICT or in the context in which it is applied. The development of metacognitive knowledge and skills are essential to the application of cognitive knowledge and skills in a setting different from that in which they were developed, and discussion of a problem-solving strategy is important in fostering metacognition (Tanner and Jones 1994). There is some evidence that such talk occurs at home (Monteith 1998), but unfortunately schools often require too little planning, monitoring, decision making and evaluation of work from pupils (Kennewell, et al. 2000).

\section{CONCLUSION}

If children's ICT capability is to develop rapidly in the early years of schooling so as to aid learning from activities across the curriculum, it is clearly sensible for approaches to ICT use in school and home to be coordinated as far as possible. There is little point in trying to make them identical; rather, the features of each setting that enhance learning should be developed and a liaison fostered in order to produce a whole greater than the sum of the parts.

Children do not tend to make links between their activities in home and school without help. Teachers should try to replicate the conditions of "hard fun": viz. a large learning gap, with unfamiliar constraints but high levels of affordance. They should also recognise the inefficiency of "bricolage" - a wide range of routines but an incomplete range of techniques and limited knowledge of processes - and help children to develop and apply more formal knowledge of ICT through direct teaching and reflective activity. Finally, they should promote and develop metacognitive skills so that children can better regulate their home ICT activity themselves. Parents should continue to provide time for exploration and help with using efficient techniques, while providing helpful constraints in the form of expectations for learning with ICT, rather than merely imposing restrictions on ICT use.

\section{REFERENCES}

Birnbaum, I. (1990) The assessment of IT capability. Journal of Computer Assisted Learning $688-97$.

Downes, T. (1998) Using the computer at home. In M. Monteith (ed.) IT for Learning Enhancement 61-78. Exeter: Intellect. 
Harrison, C., Fisher, T., Haw, K., Lewin, C., Mavers, D., Scrimshaw, P. and Somekh, B. (2001) ImpacT2: Emerging Findings from the Evaluation of the Impact of Information and Communication Technologies on Pupil Attainment. London: DfES

Kennewell, S. (1993) Changes in Strategies for Teaching and Learning Across Primary/Secondary Transfer. Swansea: University of Wales Swansea.

Kennewell, S. (2001) Using affordances and constraints to evaluate the use of ICT in teaching and learning. Journal of Information Technology and Teacher Education 10 101-116.

Kennewell, S. (2002) Good practice in teaching ICT as a subject at Key Stage 4. Coventry: Unpublished report to BECTA.

Kennewell, S., Parkinson, J. and Tanner, H. (2000) Developing the ICT Capable School. London: RoutledgeFalmer.

Monteith, M. (1998) The place of learning. In M. Monteith (ed.) IT for Learning Enhancement 61-78. Exeter: Intellect.

Papert, S. (1996) The Connected Family: Bridging the Digital Generation Gap. Atlanta, GA: Longstreet Press.

Squires, D. and McDougall, A. (1996) Software evaluation: A situated approach, Journal of Computer Assisted Learning 12 146-161.

Sutherland, R., Facer, K., Furlong, R., and Furlong, J. (2000a) SCREEN PLAY: An exploratory study of children's techno-popular culture. Report to the Economic and Social Science Research Council. http://www.bris.ac.uk/Depts/Education/fullresultsabbreviated.doc.

Sutherland, R., Facer, K., Furlong, R., and Furlong, J. (2000b) A new environment for education? The computer in the home. Computers and Education 34 195-212.

Tanner, H. F. R. and Jones, S. A. (1994) Using peer and self assessment to develop modelling skills with students aged 11 to 16: A socio-constructive view. Educational Studies in Mathematics 27 413-431.

Teacher Training Agency (1998) The Use of ICT in Subject Teaching: Expected Outcomes for Teachers. London: Teacher Training Agency and the Departments of Education.

\section{BIOGRAPHY}

Steve Kennewell is a former mathematics and ICT teacher. He leads an initial teacher education course in ICT as a specialist subject and is director of the taught graduate studies programme in the Department of Education, University of Wales Swansea. He is the editor of Computer Education and has jointly written two books concerning developing ICT capability and teaching ICT as a subject. He is a member of IFIP's Working Group 3.5. 